\title{
Relevance of Education for Sustainable Development to Zambian High School Geography: A Survey of High Schools in Lusaka City
}

\author{
by \\ Timothy Kamuzu Phiri
}

\section{ABSTRACT}

Geography is one of the subjects offered in all high schools in Zambia. At the time this study was conducted in the year 2010, five years after the declaration of the Decade of Education for Sustainable Development (ESD) (2005-2014), ESD had not yet been incorporated at high school level. The study hence sought to determine the aspects of Geography that were compatible with ESD to ascertain the attitude of high school pupils towards Geography and determine ways in which the Geography syllabus could be improved vis-à-vis the need for pupils to be empowered to thrive in their local environments. A descriptive survey research design was used and information was gathered through group discussions (for the pupils) and questionnaires (for the pupils and Geography Heads of Section). The study found that ESD could make a contribution to Geography in the areas of field projects, personal hygiene and health, sexual education, intergenerational transmission of knowledge, use of indigenous knowledge and localisation of the Geography syllabus. The study found that though pupils were interested in Geography as reflected by their general good performance in examinations, nonetheless negative attitudes existed towards Geography because of its detachment from pupils' personal environments, excessive use of teacher-centred methods and the bulky nature of the Geography syllabus.

\section{INTRODUCTION}

Geography is one of the subjects offered in the Zambian National Educational Curriculum at primary, basic, high school and tertiary levels. The unique characteristics of Geography make it a potential vehicle for incorporating ESD (UNESCO, 2009: 1). This study attempted to determine the relevance of ESD to the Geography syllabus of the year 2010 to high schools in Zambia with specific reference to the high schools in the city of Lusaka. ESD is a vision of education that seeks to empower people to assume responsibility for creating a sustainable future. ESD is a new concept that high schools in the third world are grappling with.

In view of ESD being a new approach to education that was being introduced in most countries around the world, including Zambia at tertiary level, there was clearly a need to find out how best ESD could be integrated into the Geography syllabus for Zambian high schools. There was a gap of knowledge with regards to ESD in the Zambian educational system at high school level. The purpose of this study was to determine whether or not ESD was relevant and compatible with the Zambian high school Geography syllabus as of the year 2010 . 


\section{Methods}

The research instrument used was a descriptive survey. The study collected its primary data from a sample size of 411 respondents. The respondents comprised 400 Grade twelve pupils, ten Geography heads of section and one curriculum development Geography specialist. The pupil sample size was collected from a population of 19761 pupils and twenty Geography heads of section. There was only one Geography curriculum development specialist that worked for the Curriculum Development Centre (CDC) at the time of this study.

\section{Methods of Primary Data Collection}

The primary data collection instruments used were questionnaires and focus group discussions.

\section{Questionnaires}

The questionnaires were prepared for the pupils and Geography heads of section at the visited high schools. The questionnaires comprised questions that were both closed and open ended in form. The questionnaires were given out to the selected pupils who filled them in. The researcher was present to offer clarifications to the respondents. Where necessary, follow-up questions were asked after the pupils and Geography subject specialist had finished filling in their questionnaires.

\section{Focus Group Discussions}

The researcher purposively sampled Geography pupils as the ideal source of information. A sample of pupils from among all the pupils taking Geography was selected using the lottery method which is a random sampling method. Those selected for the discussions were placed in four groups of ten pupils each and the discussions were facilitated by the researcher himself. The focus group discussions offered the pupils a friendly environment in which they could open up and talk freely.

\section{Sampling Methods}

The following sampling procedures were used in this study.

\section{Cluster Sampling Method and Lottery Sampling Method}

The cluster sampling method was used because the population of pupils to be covered by the study was large: the total number of high school pupils in the city of Lusaka at the time of the study was 19761 (excluding Academic Production Unit pupils). The second reason why the cluster sampling method was used was to ensure that there was no gender bias in the selection of the research sample. Hence, the twenty high schools 
in the city of Lusaka were clustered into three clusters. Cluster one was for the girls' high schools; Kabulonga, Matero, Munali, Roma and St Mary's. Cluster two was for the boys' high schools; Matero, Munali and Kabulonga. Cluster three compromised all the remaining co-education high schools; Arakan, Chelston, Chilenje, Chinika, Chunga, David Kaunda, Kamulanga, Libala, Lusaka and Olympia. Because the maximum number of boys' high schools from cluster three was three, three more schools were picked through the lottery method from cluster one. This brought the number of schools selected for the study to six. Four more schools were selected from cluster three using the lottery method to bring the total number of schools sampled for the study to ten.

\section{Purposive Sampling Method and Lottery Sampling Method}

From each of the ten selected schools, the Grade twelve pupils were selected purposively as the focus of the study. From each selected school of the single sex schools, forty Grade twelve pupils taking Geography were picked through the random sampling lottery method in order to make sure that each of the pupils that took Geography at high school level in the targeted schools had an equal opportunity to be selected. In the co-education schools girls and boys were clustered in two groups from which twenty pupils of each sex were picked using the random sampling lottery method to come up with a total of forty pupils. The total pupil sample size from all the ten schools was 400. In the lottery method, names of the pupils or units were written on slips of paper and were put into a box. Then the slips of paper were mixed thoroughly and a number of slips equal to the number of pupils to make the sample were picked from the box. The names on the papers picked randomly from the box constituted the sample. This was the method used to pick the sample of pupils to answer questionnaires and be part of the focus group discussions. One Geography head of section was purposively picked from each school. This brought the total of Geography heads of section to ten. 
Table 1: Breakdown of Sampled Pupils from the Sampled Institutions

\begin{tabular}{|c|l|c|c|}
\hline S/N & Name of Sampled Institutions & \multicolumn{2}{|c|}{ Sample Size } \\
\hline \multicolumn{2}{|l|}{} & Pupils & Heads of Section \\
\hline 1. & Chelston High School & 40 & 1 \\
\hline 2. & Kamwala High School & 40 & 1 \\
\hline 3. & Chunga High School & 40 & 1 \\
\hline 4. & Lusaka High School & 40 & 1 \\
\hline 5. & Matero High School & 40 & 1 \\
\hline 6. & Kabulonga Girls High School & 40 & 1 \\
\hline 7. & Munali Girls High School & 40 & 1 \\
\hline 8. & Kabulonga Boys High School & 40 & 1 \\
\hline 9. & Matero Boys Secondary & 40 & 1 \\
\hline 10. & Munali Boys High School & 40 & 1 \\
\hline 11. & Curriculum Development Centre & N/A & 11 \\
\hline & Total & $\mathbf{4 0 0}$ & $\mathbf{1 1}$ \\
\cline { 2 - 4 } & Grand Total & & $\mathbf{4 1 1}$ \\
\hline
\end{tabular}

Source: Field Data, 2012

\section{OBJECTIVES OF THE STUDY}

The following were the objectives of the study:

- To determine the possible contribution of ESD to the Geography syllabus in the Zambian High School Curriculum.

- To ascertain the attitude of high school pupils towards Geography as a vehicle for ESD.

- To determine what improvements could be made to the Geography syllabus vis-à-vis need of pupils to be empowered to thrive in their immediate local environment as a core requirement of ESD.

\section{RESULTS}

The following were the findings of the study based on the earlier mentioned objectives:

\section{Potential Contribution of ESD to Geography}

This section presents findings in relationship to one of the research objectives of this study, which is, the possible contribution of ESD to Geography. The probable linkages between ESD and Geography were the key areas of interest. In the following subsection the study addresses the contribution of Geography to the personal needs of pupils. 


\section{Relevance of Geography Content to Pupils' Personal Needs}

Upon being asked about the relevance of Geography content to their personal lives, 85 per cent $(87 \%)$ of the pupils indicated that it was not of any relevance. Only 15 per cent of the pupils were of the opinion that they personally benefited from the information they got from Geography in the classroom.

\section{Table 2: Relevance of Geography to Pupils' Personal Needs}

\begin{tabular}{|c|c|c|}
\hline Response & Frequency & Percentage (\%) \\
\hline Yes & 60 & 15 \\
\hline No & 340 & 85 \\
\hline Total & $\mathbf{4 0 0}$ & $\mathbf{1 0 0}$ \\
\hline
\end{tabular}

Source: Field Data, 2012

These results indicated that the majority pupils did not see the connection between Geography and their personal needs.

\section{Relationship between Geography and the Pupils'Immediate Environment}

The study revealed that 83 per cent $(83 \%)$ of the pupils saw no relationship between Geography and their immediate environment. It was also revealed that 17 per cent $(17 \%)$ of the pupils were of the opinion that Geography was related to their local environment.

Table 3: Relationship between Geography and the Pupils' Immediate Environment

\begin{tabular}{|c|c|c|}
\hline Response & Frequency & Percentage (\%) \\
\hline Yes & 68 & 17 \\
\hline No & 332 & 83 \\
\hline Total & $\mathbf{4 0 0}$ & $\mathbf{1 0 0}$ \\
\hline
\end{tabular}

Source: Field Data, 2012

The majority of the pupils indicated that Geography spent more time dealing with topics and content that did not affect them directly and was detached from their local environments.

\section{Influence of Geography on the Pupils' Perception of their Tribes and Cultures}

As shown in the table below the study revealed that 22 per cent of the pupils were of the opinion that Geography offered them knowledge related to their tribes and cultures. Seventy-eight per cent of the pupils disagreed and were of the opinion that what they learnt in class was not related to their tribes and cultures. 
Table 4: Influence of Geography on Pupils' Perceptions of their Cultures and Tribes

\begin{tabular}{|c|c|c|}
\hline Response & Frequency & Percentage (\%) \\
\hline Yes & 88 & 22 \\
\hline No & 312 & 78 \\
\hline Total & $\mathbf{4 0 0}$ & $\mathbf{1 0 0}$ \\
\hline
\end{tabular}

Source: Field Data, 2012

The findings revealed that the majority of the pupils saw the connection between their culture/tribe and what they learnt in Geography. Only a few pupils thought there was a connection based on a few of topics they connected to their tribes (e.g. the transhumance topic on the Lozi and the Chitemene agricultural system amongst the Bemba and Kaonde/Lunda).

\section{Opportunity of Geography Pupils to Learn from Grandparents, Parents or Guardians}

The respondents were asked to mention whether Geography offered them an opportunity to learn from their grandparents, parents or guardians. Eleven per cent (11\%) of pupils said they had an opportunity to learn from their grandparents, parents or guardians.

Table 5: Opportunity of Geography Pupils to Learn from Grandparents, Parents or Guardians

\begin{tabular}{|c|c|c|}
\hline Response & Frequency & Percentage (\%) \\
\hline Yes & 44 & 11 \\
\hline No & 356 & 89 \\
\hline Total & $\mathbf{4 0 0}$ & $\mathbf{1 0 0}$ \\
\hline
\end{tabular}

Source: Field Data, 2012

Eighty-nine per cent $(89 \%)$ of the pupils said they did not have the opportunity to learn from their guardians because the Geography content in class did not offer such an opportunity. To the majority of the pupils, Geography did not seem to facilitate the transmission of knowledge from one generation to another.

\section{Pupils' Attitudes towards Geography}

This section presents the findings vis-à-vis the second research objective of this research, which is to ascertain the attitudes of pupils towards Geography.

\section{Relevance of Geography to Pupils' Future Career Prospects}

Forty-eight per cent (48\%) of the pupils indicated that Geography as a class subject was vital in their prospective future careers. The study further revealed that 49 per 
cent $(49 \%)$ of the pupils did not think Geography offered them any career option mostly because they did not know or had not yet decided what they wanted to do after finishing their high school education.

Table 6: Pupils Perception on the Relevance of Geography to Career Prospects

\begin{tabular}{|c|c|c|}
\hline Response & Frequency & Percentage (\%) \\
\hline Yes & 192 & 48 \\
\hline No & 196 & 49 \\
\hline Not sure & 12 & 3 \\
\hline Total & $\mathbf{4 0 0}$ & $\mathbf{1 0 0}$ \\
\hline
\end{tabular}

Source: Field Data, 2012

Three per cent (3\%) of the pupils were not sure whether or not Geography had anything to do with their future career prospects. The study revealed that a considerable number of pupils, 52 per cent (52\%) in total could not see the relevance Geography had to their future career endeavours.

\section{Perceptions of Pupils on Sex Education in Geography}

The results on whether or not the pupils thought they got enough information on sex education from Geography were as follows; forty-one per cent (41\%) of the pupils indicated that there was coverage of sex education under the topic: Population Studies in Zambia.

\section{Table 7: Perceptions of Pupils on Sex Education in Geography}

\begin{tabular}{|c|c|c|}
\hline Response & Frequency & Percentage (\%) \\
\hline Yes & 164 & 41 \\
\hline No & 236 & 59 \\
\hline Total & $\mathbf{4 0 0}$ & $\mathbf{1 0 0}$ \\
\hline
\end{tabular}

Source: Field Data, 2012

Fifty-nine per cent $(59 \%)$ of the pupils indicated that the Geography syllabus did not have enough material on sex education. The key sex related issue covered under Population Studies in Zambia was related to HIV and AIDS, however most of the pupils indicated that the topic did not deal with sexuality and its consequences in depth.

\section{Areas of Possible Improvement in Geography}

The following were the findings of the study with regard to areas of Geography that needed improvement. 


\section{Coverage of Geography Syllabus before Examinations}

It was important for the study to determine whether or not the teachers of Geography actually managed to cover all the content found in the Geography syllabus. This was vital because it offered the researcher an opportunity to know whether or not the teachers managed to cover the entire Geography syllabus in three years (from Grade 10 to Grade 12). Feedback from the pupils also helped to confirm the validity of responses from Geography section heads on the same matter.

Table 8: Coverage of Geography Syllabus before Examinations

\begin{tabular}{|c|c|c|}
\hline Response & Frequency & Percentage (\%) \\
\hline Yes & 12 & 3 \\
\hline No & 388 & 97 \\
\hline Total & $\mathbf{4 0 0}$ & $\mathbf{1 0 0}$ \\
\hline
\end{tabular}

Source: Field Data, 2012

Table 8 represents the feedback from the pupils on whether or not they had covered the entire syllabus prior to the final Grade twelve Geography examinations. Ninetyseven per cent $(97 \%)$ of the pupils indicated that they did not cover all the topics in the Geography syllabus. Only 3 per cent (3\%) of the pupils indicated that they had covered all the topics in the Geography syllabus. This information was given one week prior to the commencement of the 2010 Grade twelve final examinations.

\section{Heads of Sections' Feedback on Potential Contribution of ESD to Geography}

This section presents the study's findings as gathered from the Geography heads of sections, which related to the first objective: potential contribution of ESD to Geography. This section looks at the probable linkages between Geography and ESD.

\section{Use of Outdoor Activities in the Teaching of Geography}

It was vital to find out from the heads of section whether or not they used outdoor activities as part of activities for teaching Geography. All the ten heads of section for Geography indicated that they used outdoor activities. This represented a 100 per cent affirmative response. This feedback from section heads contradicted the findings among the pupils of whom only 18 per cent (18\%) acknowledged the use of outdoor activities in Geography lessons. Having looked at the use of outdoor activities in the teaching of Geography, the next subsection presents the findings on whether or not the teachers have any knowledge of ESD.

\section{Awareness of Education for Sustainable Development amongst Geography Teachers}

It was important to find out from the Geography heads of section just how familiar they were with the concept or approach of ESD to education. This was important to know because ESD is a modern and vital approach of education for every teacher to know. 
Table 9: Awareness of ESD amongst Geography Teachers

\begin{tabular}{|c|c|c|}
\hline Response & Frequency & Percentage (\%) \\
\hline Yes & 160 & 40 \\
\hline No & 240 & 60 \\
\hline Total & $\mathbf{4 0 0}$ & $\mathbf{1 0 0}$ \\
\hline
\end{tabular}

Source: Field Data, 2012

Only 40 per cent (40\%) of the Geography heads of section indicated that they were aware of the approach of ESD. Sixty per cent (60\%) of the Geography heads of section said they were not aware of ESD.

\section{Heads of Sections' Feedback on Attitudes of Pupils towards Geography}

This section presents the data collected from the Geography section heads which related to attitudes of pupils towards Geography. The following subsection presents the findings of the research with regard to the teaching methods the Geography heads of section noticed were most preferred by the pupils.

\section{Teaching Methods Most Preferred by Pupils}

It was vital to find out from the heads of section which methods the pupils responded to best. This was important to help determine whether or not the teaching methods were pupil-centred or teacher-centred.

Table 10: Teaching Methods Most Preferred by Pupils

\begin{tabular}{|l|c|c|}
\hline \multicolumn{1}{|c|}{ Response } & Frequency & Percentage (\%) \\
\hline Lecture & 1 & 10 \\
\hline Question and Answer (Q\&A) & 1 & 10 \\
\hline Lecture and Q \& A & 6 & 60 \\
\hline At least Three Methods & 2 & 20 \\
\hline Total & $\mathbf{1 0}$ & $\mathbf{1 0 0}$ \\
\hline
\end{tabular}

Source: Field Data, 2012

Ten per cent $(10 \%)$ of the Geography heads of section indicated that the pupils responded best to the lecture method of teaching. A further 10 per cent said the pupils responded best to the question and answer method. Sixty per cent $(60 \%)$ of the respondents indicated that the pupils responded best to a combination of the lecture method and question and answer method. Twenty per cent (20\%) of the Geography heads of section indicated that the pupils responded best to a combination of three or more teaching methods.

\section{General Attitude of Pupils towards Geography as Subject}

The study sought to find out what the attitude of the key beneficiary of Geography, the pupil, was towards the subject. The possible use of Geography as a vehicle for ESD 
can only be viable if pupils have a positive attitude towards the subject. Twenty per cent $(20 \%)$ of the Geography heads of section indicated that 20 per cent $(20 \%)$ of the pupils had a 'good' attitude towards Geography.

Table 11: General Attitude of Pupils towards Geography

\begin{tabular}{|l|c|c|}
\hline Response & Frequency & Percentage (\%) \\
\hline Very Good & 2 & 20 \\
\hline Good & 5 & 50 \\
\hline Fair & 0 & 0 \\
\hline Poor & 0 & 0 \\
\hline Very Poor & 3 & 30 \\
\hline Total & $\mathbf{1 0}$ & $\mathbf{1 0 0}$ \\
\hline
\end{tabular}

Source: Field Data, 2012

Thirty per cent $(30 \%)$ of the heads of section indicated that the attitude of pupils towards Geography was 'fair', while 50 per cent $(50 \%)$ indicated that the attitude of pupils towards Geography was 'poor'. None of the respondents indicated the options 'very good' or 'very poor' in their responses. Ironically, all the Geography heads of section indicated that their pupils had interest in Geography. The reasons given for this interest were:

- Pupils' participation in class and their ability to do their homework.

- Pupils' performance in class and curiosity by posing a lot of questions in class.

- The fact that some of the pupils chose Geography as an option instead of history.

- Because the pupils used their free time to make further enquiries on particular topics.

- The good performance in the grade twelve Geography examinations.

\section{Performance of Grade Twelve Pupils in Geography Final Examinations}

All the heads of section expressed satisfaction with the performance of their pupils in the Geography finals examinations over the previous five years.

Table 12: Performance of Grade 12 Pupils in Geography Final Examinations

\begin{tabular}{|l|c|c|}
\hline Response & Frequency & Percentage (\%) \\
\hline Very Good & 3 & 30 \\
\hline Good & 7 & 70 \\
\hline Fair & 0 & 0 \\
\hline Poor & 0 & 0 \\
\hline Very Poor & 0 & 30 \\
\hline Total & $\mathbf{1 0}$ & $\mathbf{1 0 0}$ \\
\hline
\end{tabular}

Source: Field Data, 2012 
Seventy percent $(70 \%)$ of the Geography section heads categorised their pupils' performance as 'good'. Thirty per cent $(30 \%)$ categorised their pupils' examination performance as 'very good'. There appeared to be a relationship between interest in Geography and the performance of pupils in the final examinations.

\section{Heads of Sections' Areas of Potential Improvement in Geography}

This section presents the data collected from the heads of section that was related to areas in Geography that require improvement. The following subsection looks at the relevance of field projects to the localisation of Geography.

\section{Relevance of Field Projects to the Localisation of Geography}

Localisation is a critical factor in the incorporation of ESD into Geography and making Geography more meaningful to pupils. It was therefore important to find out whether or not the field projects played any role in the localisation of Geography.

\section{Table 13: Relevance of Field Projects to the Localisation of Geography}

\begin{tabular}{|c|c|c|}
\hline Response & Frequency & Percentage (\%) \\
\hline Yes & 4 & 40 \\
\hline No & 6 & 60 \\
\hline Total & $\mathbf{1 0}$ & $\mathbf{1 0 0}$ \\
\hline
\end{tabular}

Source: Field Data, 2012

Sixty per cent $(60 \%)$ of the heads of section indicated that the field projects did not suffice as a means of localising Geography to the local community because they were superficial and too examination-oriented. Forty per cent $(40 \%)$ of the respondents indicated that the field projects sufficed as a means of localising Geography to the local community.

\section{Coverage of Geography Syllabus}

Eighty per cent $(80 \%)$ of the heads of section indicated that their sections did not manage to cover the Geography syllabus in the stipulated three-year period from Grade ten to twelve. Only 20 per cent (20\%) indicated that their sections were able to cover the Geography syllabus in the stipulated time frame.

Table 14: Relevance of Field Projects to the Localisation of Geography

\begin{tabular}{|c|c|c|}
\hline Response & Frequency & Percentage (\%) \\
\hline Yes & 2 & 20 \\
\hline No & 8 & 80 \\
\hline Total & $\mathbf{1 0}$ & $\mathbf{1 0 0}$ \\
\hline
\end{tabular}

Source: Field Data, 2012 
Amongst the reasons given for the failure to cover the syllabus were the following:

- The syllabus was too bulky to cover in three years.

- The delayed reporting of pupils in Grade ten to school after being selected from Grade nine meant the entire term one of Grade ten is forfeited as they officially report one month before the term ends.

- Inclusion of irrelevant topics in physical Geography such as glaciations and volcanism.

- The commencement of examinations in October, in the third term of Grade twelve, meant that only one month in the term is available for serious teaching.

\section{DISCUSSION OF FINDINGS}

This section presents interpretations of the analysed data. This discussion is based on the objectives of the study, these being; (1) the possible contribution of ESD to Geography in the Zambian High School Syllabus, (2) the attitudes of pupils towards Geography and (3) the improvements that can be made to the Geography syllabus in relation to the need for pupils to be empowered in their local environments.

\section{Areas of Geography to which ESD can make a Contribution}

Below is the discussion of the findings in relation to the possible contribution of ESD to Geography. The essence of this section is to determine the possible linkages between ESD and Geography.

\section{The Eclectic Nature of Geography as a Classroom Subject}

Geography is the only subject in the Zambian High School Curriculum that is best suited to contribute to ESD because it possesses the characteristics of both a social and natural science. Bailey and Fox (1999), separate the components of Geography into human Geography, physical Geography and environmental Geography. These three areas encompass the social/cultural, ecological, economic and political systems. Bailey and Fox further explain that geographers are concerned with the mechanisms and interacting processes of the world's natural systems and also with the means by which human beings adopt or adapt the natural world to suit their own purposes. No subject is better equipped, to deal with the physical and aesthetic aspects of the environment and the values and cultural aspects of the human condition, than Geography.

Some of the Geography heads of section who were interviewed for the study indicated that there was a need to make Geography a compulsory subject for all pupils in high school. They said this was justified because of the inevitability and need for all people to be empowered with knowledge about their environment and sustainable practices. The Geography heads of section suggested that no one should be left out of this kind of empowerment. According to the heads of section, Geography was already compulsory at junior secondary level, hence it would be easy to make it compulsory at high school level. They emphasised the point that Geography was the only subject that had the diversity necessary to deal comprehensively with issues related to the environment and sustainability. 


\section{Geography as a Vehicle for Localisation}

There is a key emphasis in ESD of the role to be played by the individual and the individual's local surroundings (Tilbury and Wortman, 2004). The pupils and heads of section appeared to agree on the need to localise the Geography content. However, this study found that Geography only had a minor role to play in bringing the pupils closer to their environment because its syllabus was too crowded with topics that dealt with aspects that were foreign. Some of the heads of section added that though certain aspects were local, they remained very shallow and out of touch with the realities that pupils go through. Some heads of section, for example, mentioned that in spite of agriculture and tourism in Zambia being very good topics, they did not bring out the full aspects of the Zambian fabric. They emphasised that the topics dealt with Zambian issues on a very superficial level. In the words of the Geography section head for Matero Girls' High School, 'Geography is infested with too many foreign concepts'. This quotation reflected the feeling of most of the heads of section that were part of the study. She further suggested that the problem stemmed from the fact that for a long time before independence and after independence the key architects of the educational system remained the whites; the colonialists.

The changes that were part to the new Geography syllabus in the year 2001, attempted to remodel the colonial perspective into our own local perspective. However, this remodelling seems to have failed to stamp out the original white colonial mentality from the syllabus. The influence of the educational system inherited from the missionary and colonial past should not be down-played nor underestimated. Chipungu (1992: 110) supports this argument and states that:

African educational policy in Zambia was devised within the framework of an evolving colonial policy based on the reports made by the Phelps-Stokes Commission and expressed in policy statements drawn up by the Colonial Office Advisory Committee on Education formed in 1923. These provided for government assistance to missionary societies offering primary education relevant to the practical needs of rural Africans, which were assumed to be equivalent to those of blacks in the southern states of the United States of America.

The influence of missionary and colonial past can neither be ignored nor taken out of the big picture to understand why the high school Geography syllabus emphasised foreign aspects more than local indigenous aspects. A look at one of the key books used in high school Geography, 'Certificate Physical and Human Geography' by Goh Cheng Leong revealed a wide range of topics that when closely examined are detached from the local Zambian situation. In the words of one of the heads of section, 'the syllabus should be localised to meet the needs of the local community first before attempting to meet the needs of anybody else'. Clearly, the Geography syllabus covered by this study in the year 2010 bore more of a colonial face and mentality than an indigenous one. There was need to give the Geography syllabus a face that was reflective of the reality on the ground in our society. This observation was in line with the recommendations of the UNESCO Action Plan for UNDESD 2005 - 2015. 


\section{Personal Hygiene, Health and Sex Education}

The study revealed that 36 per cent (36\%) of the pupils indicated that they felt Geography offered information on personal hygiene and health. However, sixtyfour per cent $(64 \%)$ responded negatively. Upon probing those that answered in the affirmative further, they mentioned that they received this information from topics such as 'Pollution'. However, some of the heads of section indicated that whilst the topic of 'Pollution' offered some information on hygiene and health, it did not go far enough in dealing with issues of health and hygiene on a personal level. They said this was also the case if one looked at the way HIV and AIDS was handled in the syllabus under the topic 'Population'. It was not dealt with in depth.

When one considers the gravity of HIV and AIDS as a social problem not only in Southern Africa but in Zambia, it seems odd that this issue was dealt with only at a shallow level in the classroom. The Geography syllabus missed an opportunity to empower pupils with knowledge and values that could give them a whole new perspective on how to best appreciate the gravity of the social implications of their sexuality and actions in relation to HIV and AIDS.

\section{Attitudes of the Pupils towards Geography}

This section discusses the findings in relation to the attitude of the pupils towards Geography.

\section{Redefining the term 'Localisation'}

One of the key issues that this research unsurfaced was that there seemed to be a misconception with regard to the way the word, 'localisation' was used. The Oxford Advanced Learner's Dictionary (2006: 867), defines 'localise' as, 'to limit something or its effects to a particular area.' Eighty-three per cent (83\%) of the pupils indicated that Geography had little to do with their local environments. This contradicted the aspirations of the Geography syllabus which at the time of this study in the year 2010, was last revised in the year 2000 to make it more local. There was a contradiction in the way the word 'local' was viewed by the Geography syllabus and the way it has been defined above. For example, while 'Tourism in Zambia' may appear to be a local topic at first glance, it is in earnest not really a local topic but a national one. It is not local because tourism in Livingstone is as foreign or detached a topic to the pupils in the Gwembe Valley of Southern Province and Kawambwa District of Luapula Province as the topic on Glaciations in Europe. The true definition of the term local should be given with reference to an issue that is connected to the immediate environment in which the pupils live. It is this localisation, at grass-roots level, that was missing in the Geography syllabus.

The Zambianisation of the syllabus by including topics that are related to the country, in the year 2000, did not necessarily localise the syllabus. Localisation of a syllabus in relation to ESD should entail bringing it down to the level of an individual. The pupil should be able to claim personal ownership of the syllabus because they see a reflection 
of their surroundings in it. According to Bailey and Fox (1999), motivation to learn is likely to relate to the degree to which pupils perceive relevance to themselves, and can relate their learning to real situations in their own lives. This confirms the need to localise the Geography syllabus. Unless Geography begins to deal with real situations that pupils experience in their local communities, its impact on the local community will be compromised.

\section{Pupils' Interest and Attitude towards Geography}

A 100 per cent of the heads of section indicated the pupils had interest in Geography. This was a key observation because in order for the subject of Geography to be a vehicle for ESD it needs a clientele base, and that base is made up of the pupils who are the supposed beneficiaries of Geography. One of the key criteria used in measuring the interest of the pupils appeared to be tied to their performance in the final Grade twelve examinations. All the heads of section rated the performance of their pupils as 'good' or 'very good' which had a percentage distribution of 70 per cent and 30 per cent respectively. Ironically, fifty per cent $(50 \%)$ of the heads of section indicated that the attitude of pupils towards Geography was 'poor'. Thirty per cent indicated that it was 'fair' and only twenty per cent indicated it to be 'good'. When asked to clarify the contradiction between interest and attitude the heads of section that provided the 'fair' and 'poor' as responses indicated that there was a big difference between interest and attitude. One of them went a step further and stated that, 'the difference between interest and attitude is akin to that between liking and loving'. They suggested that an attitude carried a deeper meaning than an interest.

This study discovered that the interest levels among pupils for Geography were high but their attitude towards it was questionable. This can be noted in the previous paragraph. Interest is a shallow variable to use in measuring the effectiveness of a subject, because it is based on an individual's curiosity or attraction to something or an object. While an attitude, on the other hand, is tied to an action, deed is the evidence of a particular pattern of thought or belief. Hence, it can be deduced that while Geography was able to stimulate interest, it was not yet able to stimulate or inculcate actions or deeds in the pupils that reflected a particular positive pattern of thinking in relation to the environment. Localising the Geography syllabus and incorporating ESD would help to equip Geography with the methodology and values which enable it to inculcate positive sustainable behaviour.

\section{Inter-generational Learning and Culture Transmission}

One of the factors that came out as a vital component missing in improving the attitude of pupils was, the aspect of the pupils not having an opportunity to learn from their own grandparents, parents or guardians. Eighty-nine per cent (89\%) of the pupils indicated that Geography did not offer an opportunity to learn from their grandparents, parents or guardians. This is a component that is closely related to the culture of the pupils. One of the key ways through which cultural knowledge is transmitted is through the interaction between children and the older generation of their families. 
Seventy-eight per cent of the pupils felt that they did not learn anything in Geography that was of personal cultural benefit. Twenty-two per cent (82\%) of the pupils were of the view that what they learnt had some cultural benefit. Further questioning during the focus group discussions revealed that the portion of pupils that said they learnt something about their culture from Geography were actually referring to the aspects they learnt on traditional agriculture and transhumance among the Lozi of Western Province, traditional cultivation techniques of the Bemba of Northern Province and the Luvale, Lunda and Kaonde of North-Western Province. This clearly cannot qualify to be an in-depth coverage of the cultural heritage of pupils, especially when one considers the diverse ethnic and cultural mosaic of the seventy-three tribes of our country, Zambia. In support of this observation Bailey and Fox (1999: 29) state that:

Geography as a subject area, with people as its focus, has unrivalled potential for breaking down prejudices, questioning stereotypes and broadening cultural understanding. The wide range of geographical studies, from global to local level, should give the subject a head start in terms of educational opportunities.

The previous excerpt emphasises the unique role Geography can play as a bridge builder between cultures and its role as an agent for social change. However, it must be said that before any individual endeavours to understand another culture, they must understand and come to terms with their own culture first. Any individual who does not value or have a full appreciation of their culture can never have the capacity to understand let alone appreciate a different or foreign culture. We cannot begin to talk about sustainability of any sort, if we have no capacity to preserve nor sustain the cultural values and interests of the diverse ethnic groups in our country, Zambia.

\section{Attitude of Pupils vis-à-vis Career and Academic Prospects}

Forty-eight per cent of the pupils indicated that Geography as a class subject was vital to their prospective future career. They identified it as a social science that could help them get into the School of Humanities or School of Education at the University of Zambia, if their final examination results were good enough. Some of the pupils that mentioned that Geography was important to their prospective future careers gave the following as possible career options: geology, Geography teaching, becoming a pilot and a military career. This study also revealed that 49 per cent of the pupils indicated that Geography did not offer them any future career prospects. Three per cent of the pupils were not sure whether or not Geography had anything to do with career prospects.

There also appeared to be little content on human environmental issues in the Geography syllabus that the pupils could actually relate to. The more the pupils identify with human environmental issues in Geography in connection to themselves and particular careers, the better their attitudes would be towards Geography. One of the heads of section indicated that the attitude of pupils towards field projects in Geography also seemed to change once the pupils were made to realise how important the experience they got would be when they had a chance to do research in college or university later on in their lives. 


\section{Areas in Geography that need Improvement}

The following section discusses the areas of the Geography that require urgent innovation or modification.

\section{Coverage of the Geography Syllabus}

This study revealed that 97 per cent of the pupils indicated that they did not cover the entire syllabus in the three years of high school. Only 3 per cent of the pupils indicated that they managed to cover the entire syllabus in three years. Eighty per cent of the section heads indicated that it was impossible to cover the entire syllabus in three years. Further probing of the 20 per cent of the heads of section that indicated they were able to finish the syllabus revealed that they, in fact, did not cover the entire syllabus but had from experience come up with a strategy for covering topics that they assessed would give their pupils an advantage in the sections that offer options on questions to be tackled in the Geography examinations. So, in reality, what they were able to cover completely were the schemes of work which comprised topics selectively picked based on the Geography sections' experience of how Geography questions came in the Grade twelve final Geography examinations.

\section{Knowledge of ESD amongst High School Teachers}

Sandell et al. (2005), suggest that ESD is an approach to EE which gives students the opportunity to acquire knowledge and skills so that they can actively and critically evaluate different perspectives of environmental and developmental issues. In this way students develop the ability to engage in democratic discussions concerning how best to create a sustainable society and a sustainable world. Sandell and colleagues add that the teaching content includes the relationship between local and global problems as well as between the past, present and future. The focus clearly is on SD and the related topics of economics, society and ecology. It is worth noting here that the only subject in the Zambian high school curriculum that has aspects of economics, society and ecology is Geography. Hence, the teachers of Geography should take the lead and be the first to be given the opportunity for capacity building in ESD. We currently live in a world where the need for SD is more real than ever before and the only way to bring values and principles of SD to the classroom is by incorporating ESD into Geography. The capacity building of Geography teachers with ESD is a fundamental part of accomplishing the aspirations of sustainable living.

The study revealed that only 40 per cent (40\%) of the Geography section heads had an idea about ESD. However, further probing of the heads of section who said they were aware of ESD revealed that they actually referred to, with knowledge on SD and not ESD itself. Sixty per cent (60\%) of the Geography heads of section indicated that they were not aware of ESD. 


\section{Field Projects}

Field projects, when used correctly, are one of the best ways of learning available to pupils. They allow pupils to interact with the environment and get to discover local issues that they can investigate and offer solutions to. Forty per cent $(40 \%)$ of the heads of section indicated that field projects were an important aspect of the Geography syllabus and sufficed as a means of localising the Geography syllabus. Sixty per cent of the heads of section for Geography acknowledged the importance of the field projects but indicated that in their current form they did not suffice as a means of localising the Geography syllabus and had a minimal impact. The following flaws were noted.

Firstly, the field projects were too examination-oriented instead of being skilloriented. The field projects were conducted as a requirement for the examinations. Not much attention was given to whether or not the pupils were being empowered with relevant skills that will last them a life time. The motivation behind the commencement of work on the field projects was not the acquisition of knowledge or skills but the pressure of approaching Geography examinations to which the field project accounts for twelve marks out of the total marks. Another factor that clearly indicated that the field projects were pro-examination was the observation that most of the pupils had no experience of conducting a field project prior to the official field projects they conducted as part of the Grade twelve final examinations.

\section{CONCLUSION}

In conclusion, the study found that ESD could make a contribution to Geography in the areas of field projects, personal hygiene and health, sex education, inter-generational transmission of knowledge, use of indigenous knowledge and localisation of the Geography syllabus. The attitude of pupils towards Geography was found to be mostly negative and the following came out as possible reasons: prominence of foreign items in Geography topics at the expense of local issues and cultural knowledge; orientation of the Geography syllabus towards examinations instead of skill and knowledge empowerment of pupils; excessive use of teacher-centred methods at the expense of pupil-centred methods and the bulky nature of the Geography syllabus which made it impossible to cover in three years. In relation to the dominance of foreign topics this study established that the Geography syllabus was still influenced by western inclinations and perspectives which have been part of the education system since pre-independence colonial times and the early post-independence era. The study also revealed the difference between an attitude and interest. Whilst interest in Geography was high amongst pupils, their attitude towards it was largely negative.

The Geography syllabus was found to require the following modifications to help it empower the pupils in their local environments: re-orientation of the Geography syllabus to make its core purpose the empowerment of pupils with relevant knowledge and skills and not just the passing of examinations; to have teachers trained in ESD so that its incorporation into the syllabus is easier and meaningful; to find a way of 
adjusting the commencement period for classes in the first term of Grade 10, to reorient the way field projects are handled and make them less examination-oriented and to make the Geography syllabus leaner and easier to cover.

\section{REFERENCES}

Bailey, P. and Fox, P. (1999), Geography Teachers' Handbook, Colocraft Limited. London: England.

Chipungu, S.N. (1992), Guardians in Their Time-Experiences of Zambians Under Colonial Rule, 1890-1964. London: Macmillan.

Oxford Advanced Learners Dictionary (2006). London: Oxford Press.

Sandell, K., Ohman, J. and Ostman, L. (2003), Education for Sustainable and Development: Nature, School and Democracy Student Literature, Lund, Sweden. Stir, J.(2003), Restructuring Teacher Educationfor Sustainability: Student Involvement through a 'Strengths Model', Griffith University, Queensland, Australia. //campussostenble.mty.itesm.mx/EMSUIII/PDF_articulos_completos/a01_104_j_stir_full. pdf [retrieved 1 October 2010].

Tilbury, D. and Wortman, D. (2004), Engaging People in Sustainability. Netherlands: Kluwer Academic Publishers.

UNESCO (2009), Education for Sustainable Development Goals. Available at http:// portal.unesco.org/education/es/ev/php [accessed 5 February 2010]. www.esd-world-conference-2009.org [accessed 26 January 2010]. 